\title{
Hydrogen Production via a Commercially Ready Inorganic membrane Reactor
}

Semi-Annual Technical Progress Report

Reporting Period: October 1, 2006 to March 31, 2006

Paul K. T. Liu

Project Director

May 31, 2006

PREPARED FOR THE UNITED STATES

DEPARTMENT OF ENERGY

Under Cooperative Agreement

No. DE-FC26-03NT41852

By

MEDIA AND PROCESS TECHNOLOGY, INC.

1155 William Pitt Way

Pittsburgh, PA 15238 


\section{$\underline{\text { Disclaimer }}$}

This report was prepared as an account of work sponsored by an agency of the United States Government. Neither the United States Government nor any agency thereof, nor any of their employees, makes any warranty, express or implied, or assumes any legal liability or responsibility for the accuracy, completeness, or usefulness of any information, apparatus, product, or process disclosed, or represents that its use would not infringe privately owned rights. Reference herein to any specific commercial product, process, or service by trade name, trademark, manufacturer, or otherwise does not necessarily constitute or imply its endorsement, recommendation, or favoring by the United States Government or any agency thereof. The views and opinions of authors expressed herein do not necessarily state or reflect those of the United States Government or any agency thereof. 


\section{$\underline{\text { Abstract }}$}

One of the technical barriers for ceramic membranes is its scale up potential. The conventional ceramic membranes/modules originally developed for liquid phase applications are costly and not suitable for high temperature applications. One of the objectives under this project is the development of a ceramic membrane/module, which is economical and suitable for high temperature applications proposed under this project (200$300^{\circ} \mathrm{C}$ ). During this period, we initiated the fabrication of a prototype ceramic membrane module which can be (i) qualified for the proposed application temperature, and (ii) cost acceptable for large scale applications. A prototype ceramic membrane bundle (3" diameter and $35^{\prime \prime} \mathrm{L}$ ) has been prepared, which passes the temperature stability requirement. It also meets the low end of the burst pressure requirement, i.e., 500-750 psi. In the next period, we will continue the improvement of this prototype module to upgrade its burst pressure to 1000 to 1500 psi range. In addition, bench-top experimental study has been conducted in this period to verify satisfactorily the simulated results for the process scheme developed in the last report, which took into the consideration of streamlining the pre- and posttreatment. The sensitivity analysis indicates that membrane surface area requirement is a key operating parameter based upon the criteria of the $\mathrm{CO}$ conversion, hydrogen recovery and CO impurity level. A preliminary optimization study has been performed in this period based upon the key operating parameters determined above. Our result shows that at 40 bar feed pressure a nearly complete CO conversion and $>95 \%$ hydrogen recovery can be achieved with the $\mathrm{CO}$ impurity level at $\sim 3500 \mathrm{ppm}$. If the hydrogen recovery ratio is lowered, the $\mathrm{CO}$ impurity level can be reduced further. More comprehensive optimization study will be performed in the $2^{\text {nd }}$ half of Yr III to focus on the reduction of the CO impurity level with a reasonable hydrogen recovery ratio. 


\section{TABLE OF CONTENTS}

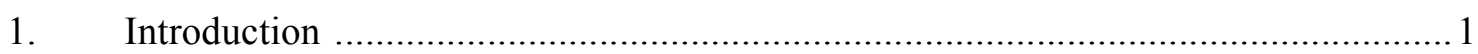

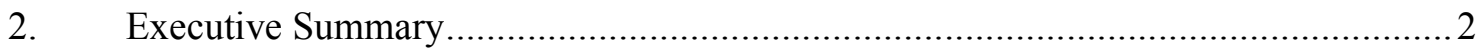

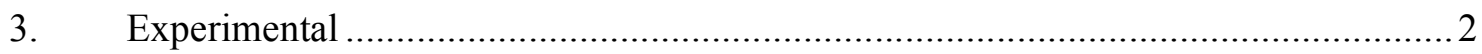

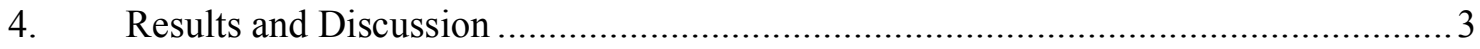

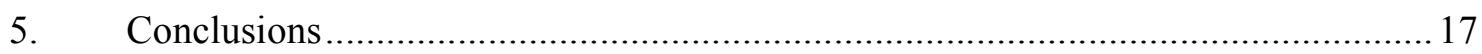

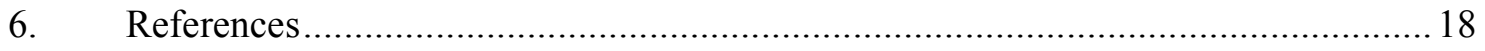

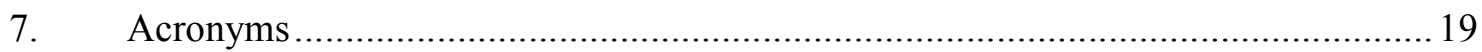




\section{$\underline{\text { List of Graphical Materials }}$}

\section{Figures}

Figure 1 Candle filter ceramic membrane bundle and module (bottom) and patented high temperature packing/seal design (top) and a single element pilot scale module

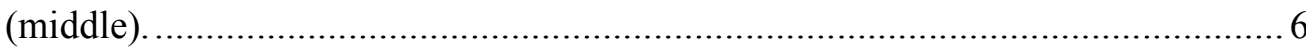

Figure 2 Experimental vs predicted CO conversion using a CMS membrane as a reactor.... 7

Figure 3 Effect of sweep ratio (as a fraction of the feed flow rate) on the CO conversion: experimental vs predicted. The feed condition used is the same as the one used

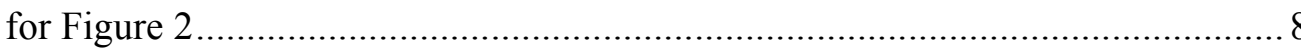

Figure 4 Effect of feed pressure on the CO conversion using a CMS-WGS-MR (the feed pressure as indicated, the rest of the condition is presented in text as the base case)

Figure 5 Effect of W/F on the CO conversion (the W/F used as noted, the rest of the operating condition is presented in the text as the base case) 10

Figure 6 Effect of sweep ratio on the CO conversion (sweep ratio as a fraction of the feed stream as noted, the rest of the condition is presented in the text as the base case) 11

Figure 7 Effect of feed pressure on the hydrogen recovery ratio (the feed pressures as noted, the rest of the conditions are presented in the text as the base case).

Figure 8 Effect of $\mathrm{W} / \mathrm{F}$ on hydrogen recovery ratio (the $\mathrm{W} / \mathrm{F}$ used as noted, the rest of the conditions are presented in the text as the base case)

Figure 9 Effect of sweep ratio on hydrogen recovery ratio (the sweep ratio used as indicated, the rest of the conditions are presented in the text as the base case)..... 14

Figure 10 Effect of feed pressure on the CO impurity level in the hydrogen recovered (the feed pressure as noted, the rest of the conditions are presented in the text as the base case)

Figure 11 Preliminary optimization study on the proposed WGS-MR at 4 (top), 10 (middle) and 40 (bottom) bar feed pressure. The kinetics of the catalyst used here has not been verified at this high pressure range. Thus the optimization study here should be treated as preliminary. The Peclet number here represents the reactor length. The performance of $\mathrm{CO}$ conversion, hydrogen recovery and $\mathrm{CO}$ impurity are simulated against the membrane surface area for a given $\mathrm{W} / \mathrm{F}$ determined from the packed bed. 


\section{Introduction}

Fabrication of Modules for Large Scale Applications

During this period, we initiated the development of the ceramic membrane module suitable for the proposed water gas shift reaction. One of the major concerns on the use of the ceramic membrane for large scale applications is its scalability of "module". Previously we have reported the conceptual design for our ceramic membrane to overcome this barrier. Our progress in the fabrication of the proposed module is summarized in this report.

Experimental Verification of Mathematical Model for WGS-MR

Our mathematical model developed previously was experimentally verified in Year II using the feed from the coal gasifier off-gas as listed below:

\section{Component Composition}

[mol fraction]

$\begin{array}{ll}\mathrm{H} 2 & 0.29 \\ \mathrm{CO} & 0.39 \\ \mathrm{CO} 2 & 0.13 \\ \mathrm{H} 2 \mathrm{O} & 0.18 \\ \mathrm{~N} 2 & 0.01\end{array}$

In our proposed process scheme, the $\mathrm{CO}$ from gasifier will be fed to the $1^{\text {st }}$ part of the reactor with nonpervious membranes. Since the reaction kinetics of the WGS is fast under this high pressure, the membrane reactor is not a necessity. The residual unconverted $\mathrm{CO}$ can then be fed to the WGS-MR for further converison. The feed composition to the membrane reactor (MR) is presented below as an example:

$\begin{array}{lll}\text { Temp ( } & & 250 \\ & \% & \\ \mathrm{H} 2 & & 0.41 \\ \mathrm{CO} & & 0.14 \\ \mathrm{CO} 2 & & 0.28 \\ \mathrm{H} 2 \mathrm{O}(\mathrm{g}) & & 0.16 \\ \mathrm{~N} 2 & & 0.01 \\ \text { subtotal } & & 1.00 \\ \mathrm{H} 2 \mathrm{O} / \mathrm{CO} & & 1.18\end{array}$

The advantage of this scheme described in the last report is the process reliability. The WGSR is exothermic; it would make a lot of sense to perform the first stage under the adiabatic condition while its upper limit of the conversion (i.e., upper limit of the reactor temperature) can be controlled by the water content in the feed. Thus, the conversion process is self-limited without the risk of exceeding the upper allowable temperature of the catalyst. In the $2^{\text {nd }}$ reactor, the unconverted CO level is $\leq \sim 10 \%$. Thus, the reactor temperature will be kept under the maximum allowable temperature of the catalyst with our proposed membrane reactor. During this reporting period, we have performed the experimental study at this concentration range (i.e., $\sim 10 \% \mathrm{CO}$ ) to verify the accuracy of the mathematical model for the proposed scheme. 
Effect of Operating Variables on WGS-MR Performance

Once the mathematical model was verified for the operating condition proposed here. A series of simulation work was performed to identify the critical operating parameters for us to conduct an optimization study in the $2^{\text {nd }}$ half of Yr III.

\section{Executive Summary}

One of the technical barriers for ceramic membranes is its scale up potential. The conventional ceramic membranes/modules originally developed for liquid phase applications are costly and not suitable for high temperature applications. One of the objectives under this project is the development of a ceramic membrane/module, which is economical and suitable for high temperature applications proposed under this project $\left(200-300^{\circ} \mathrm{C}\right)$. During this period, we initiated the fabrication of a prototype ceramic membrane module which can be (i) qualified for the proposed application temperature, and (ii) cost acceptable for large scale applications. A prototype ceramic membrane bundle (3" diameter and 35"L) has been prepared, which passes the temperature stability requirement. It also meets the low end of the burst pressure requirement, i.e., 500-750 psi. In the next period, we will continue the improvement of this prototype module to upgrade its burst pressure to 1000 to 1500 psi range. In addition, bench-top experimental study has been conducted in this period to verify satisfactorily the simulated results for the process scheme developed in the last report, which took into the consideration of streamlining the preand post-treatment. The sensitivity analysis indicates that membrane surface area requirement is a key operating parameter based upon the criteria of the $\mathrm{CO}$ conversion, hydrogen recovery and CO impurity level. A preliminary optimization study has been performed in this period based upon the key operating parameters determined above. Our result shows that at 40 bar feed pressure a nearly complete $\mathrm{CO}$ conversion and $>95 \%$ hydrogen recovery can be achieved with the $\mathrm{CO}$ impurity level at $\sim 3500 \mathrm{ppm}$. If the hydrogen recovery ratio is lowered, the CO impurity level can be reduced further. A comprehensive optimization study will be performed in the next reporting period.

\section{Experimental}

\section{Fabrication of Modules for Large Scale Applications}

1. A multiple tube element ( 3 " diameter and 35 'L) has been successfully fabricated as a prototype unit to demonstrate our proposed concept (see Figure 1 bottom). Its configuration is similar to our existing commercial membrane elements for liquid phase applications. Major modification here is to replace the epoxy potting of the tube bundle with the high temperature ceramic potting; thus, the bundle element can take the temperature of $>500$ $600^{\circ} \mathrm{C}$.

2. Two different designs were conceived based upon this bundle concept: shell-and-tube heat exchanger-like and candle filter-like. In the shell-and-tube design the element can be mounted on two ends to the housing. In the candle filter design, the element is mounted on 
one-end only while the other end is sealed, mimicking existing candle filters used for particulates removal as shown in Figure 1 top.

Experimental Verification of Mathematical Model for WGS-MR

3. The experiment was performed at several selected W/F's to compare the predicted vs experimental $\mathrm{CO}$ conversion. In addition, we have performed the two different levels of the sweep ratio to compare its effect on conversion and CO impurity level.

\section{Effect of Operating Variables on WGS-MR Performance}

4. Using the mathematical model developed previously, we have performed sensitivity analysis to determine the effect of each key operating variable. Based upon these results we will then select critical operating variables for optimization study in the $2^{\text {nd }}$ half of Yr III. The base case selected for this sensitivity analysis is presented below:

\begin{tabular}{|c|c|}
\hline \multicolumn{2}{|c|}{ Feed Composition } \\
\hline $\begin{array}{c}\text { [mol } \\
\text { fraction] }\end{array}$ & \\
\hline $\mathrm{CO}$ & 0.15 \\
\hline $\mathrm{CO} 2$ & 0.27 \\
\hline $\mathrm{H} 2 \mathrm{O}$ & 0.18 \\
\hline $\mathrm{H} 2$ & 0.4 \\
\hline $\mathrm{N} 2$ & 0.01 \\
\hline
\end{tabular}

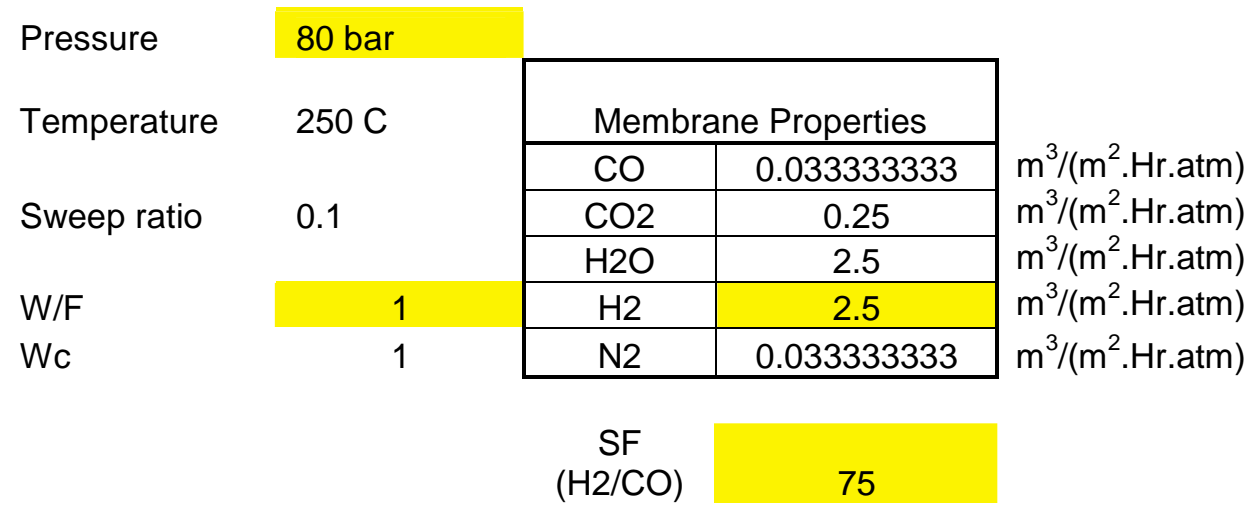

\section{Results and Discussion}

\section{Fabrication of Modules for Large Scale Applications}

1. For the heat exchanger design, fluid can be fed to either the shell or tube side. In the candle filter design; however, fluid can only be fed into the shell side while the permeate can be collected from the exit of the tube side. This latter design offers the advantage of separating the ceramic element expansion/contraction from the steel housing expansion/contraction as a result of temperature change. Thus, no mismatch would incur. The disadvantage of the candle filter is that no permeate side purge can be implemented. Since our application temperature is at $200-300^{\circ} \mathrm{C}$, we believe that the mismatch between the housing and the element could be manageable. Thus, we will continue the development of both designs.

2. The burst pressure test was also conducted in this month for the single tube as well as the element. The burst pressure for the single tube was tested up to $>1500$ psi from the outside of the tube without rupture; thus, we believe that the individual tube strength is more than adequate for the proposed application. The burst pressure of the candle filter element (3") was 500-750 psi. The failure was resulted from the pressure exerting on the tube sheet. Based upon our proposed process scheme, the pressure drop across the membrane would be in the range of 500 to 1500 psi. Although we can increase the tube sheet thickness to 
enhance the burst pressure as an option; the tube sheet is currently under redesign to accommodate the burst pressure of $>1500$ psi as an ultimate solution.

Experimental Verification of Mathematical Model for WGS-MR

3. The experimental and predicted results are presented in Figures 2 and 3. The mathematical model can predict the conversion and the effect of sweep ratio reasonably well for the feed composition suggested for the WGS-MR. In the next section, we will evaluate effects of some key parameters on the performance of the proposed WGS-MR.

\section{Effect of Operating Variables on WGS-MR Performance}

4. CO Conversion Ratio..._CO conversion is one of the performance criteria for our proposed process. In this subsection, we evaluate the effect of key operating parameters, including $\mathrm{W} / \mathrm{F}$, feed pressure and sweep ratio, on the CO conversion. The effect of feed pressure on the $\mathrm{CO}$ conversion is presented in Figure 4. The range of the pressure for this study is 40 to 120 bar. The lower pressure represents the off-gas pressure obtained from the BGL gasifier, while the upper end, 120 bar, represents the off-gas from the Texaco oxygen blown gasifier. The pressure has a very slight effect on the degree of CO conversion as shown in Figure 4. The effect of W/F on the CO conversion is presented in Figure 5. When the W/F increases from 0.5 to 1.5 , the $\mathrm{CO}$ conversion improves significantly. Since the conversion above the equilibrium is dependent upon the rate of the product removal, the higher $\mathrm{W} / \mathrm{F}$ provides a sufficient time for the reactor to remove a significant quantity of the product, hydrogen. Thus, we believe that $\mathrm{W} / \mathrm{F}$ effect is most likely resulted from the increase in the membrane surface area because the reaction kinetics under the selected operating condition, i.e., high pressure, is very fast as observed for the packed bed in the figure. The permeation rate vs reaction rate will be selected in the future for optimization study. Figure 6 presents the effect of the sweep ratio. As the effect of pressure, the sweep ratio effect is very modest on the degree of conversion. In conclusion, using the base case presented above, our simulation indicates that the $\mathrm{W} / \mathrm{F}$ has the profound effect on the degree of conversion. Further, our analysis shows that this effect is most likely resulted form the increase in the membrane surface area. The permeation rate vs the reaction rate will be chosen for our optimization study in the future.

5. Hydrogen Recovery Ratio... A membrane reactor offers the advantage of integrating the reaction and product separation into a single unit. Thus, it is very important for us to select an operating variable which can recover as much hydrogen as possible. Again we have chosen the feed pressure, $\mathrm{W} / \mathrm{F}$ and the sweep ratio to evaluate their effect on the hydrogen recovery ratio. As expected the higher the feed pressure, the higher the recovery ratio is. According to the base case selected above, the system pressure $>80$ bar can deliver a nearly complete recovery of hydrogen. When the system pressure is at $40 \mathrm{bar}$, an increase in the membrane surface area is necessary in order to achieve a high degree of hydrogen recovery. The $\mathrm{W} / \mathrm{F}$ effect is presented in Figure 8. As expected, the W/F effect is in effect can be translated in the effect of the membrane surface area. Thus, the higher the $\mathrm{W} / \mathrm{F}$ is, the more efficient the hydrogen recovery is. According to our simulation, $\mathrm{W} / \mathrm{F}$ at 1 or above is sufficient to deliver a complete hydrogen recovery. Finally the sweep ratio effect is presented in Figure 8, its effect on the hydrogen recovery is insignificant. In conclusion, the 
hydrogen recovery appears not a dominating performance criteria for the base case selected. It appears that a high degree of hydrogen recovery can be accomplished within the operating parameters we selected. During the optimization study, the CO version, not the degree of hydrogen recovery, will be selected as a primary performance criterion.

6. CO Impurity Concentration... The CO impurity is considered as an important performance criterion, in particular for fuel cell applications. Figure 8 presents the $\mathrm{CO}$ concentration as a function of the feed pressure. It appears that the feed pressure has a significant effect on the $\mathrm{CO}$ concentration. At a higher feed pressure, i.e., 120 bar, the $\mathrm{CO}$ impurity level could reach as high as $5,000 \mathrm{ppm}$ although this level is still ten times less than that from the packed bed. About 1,000 ppm can be achieved for the feed pressure at 40 bar. The simulation results indicate that the $\mathrm{CO}$ permeation could be more efficient at the high feed pressure. Thus, the high CO impurities level at 120 bar is most likely resulted from the leak of the CO during the initial stage of the reactor. Thus our optimization study should focus on the optimization of the reaction rate vs permeation rate; thus, the product conversion can be maximized and the impurity permeation could be kept at a minimum. According to the hydrogen recovery ratio vs reactor length in Figure 10, a nearly $100 \%$ hydrogen recovery is accomplished at the reactor length $<<1$. Thus, the $\mathrm{CO}$ impurities could be reduced to about $1,000 \mathrm{ppm}$ or less when the reactor is optimized.

7. Optimization Study... A preliminary optimization study based upon the above experience has been performed to get some idea about the performance of the WGS-MR under the proposed scheme. It appears that a nearly complete CO conversion and $\sim 95 \%$ hydrogen recovery can be achieved with the $\mathrm{CO}$ impurity level at $3500 \mathrm{ppm}$ for the feed side pressure at $40 \mathrm{bar}$. The $\mathrm{CO}$ impurity level can be reduced to $1500 \mathrm{ppm}$, however, the recovery ratio is reduced to $\sim 70 \%$. This simulation study should be treated very preliminary since the reaction kinetics of the catalyst has not been verified at such a high pressure. More comprehensive optimization study will be performed in the $2^{\text {nd }}$ half of Yr III to focus on the reduction of the $\mathrm{CO}$ impurity level with a reasonable hydrogen recovery ratio. 


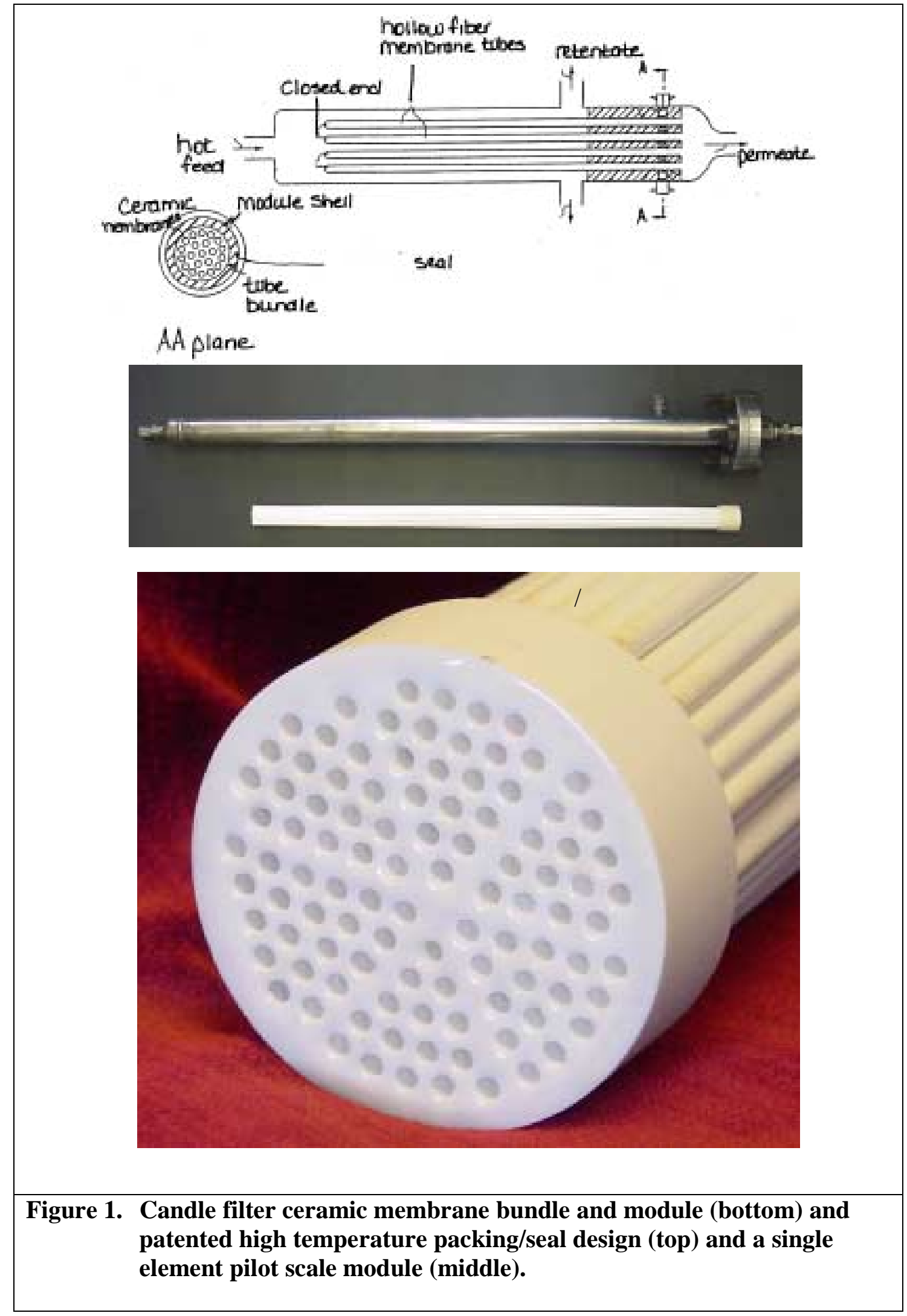




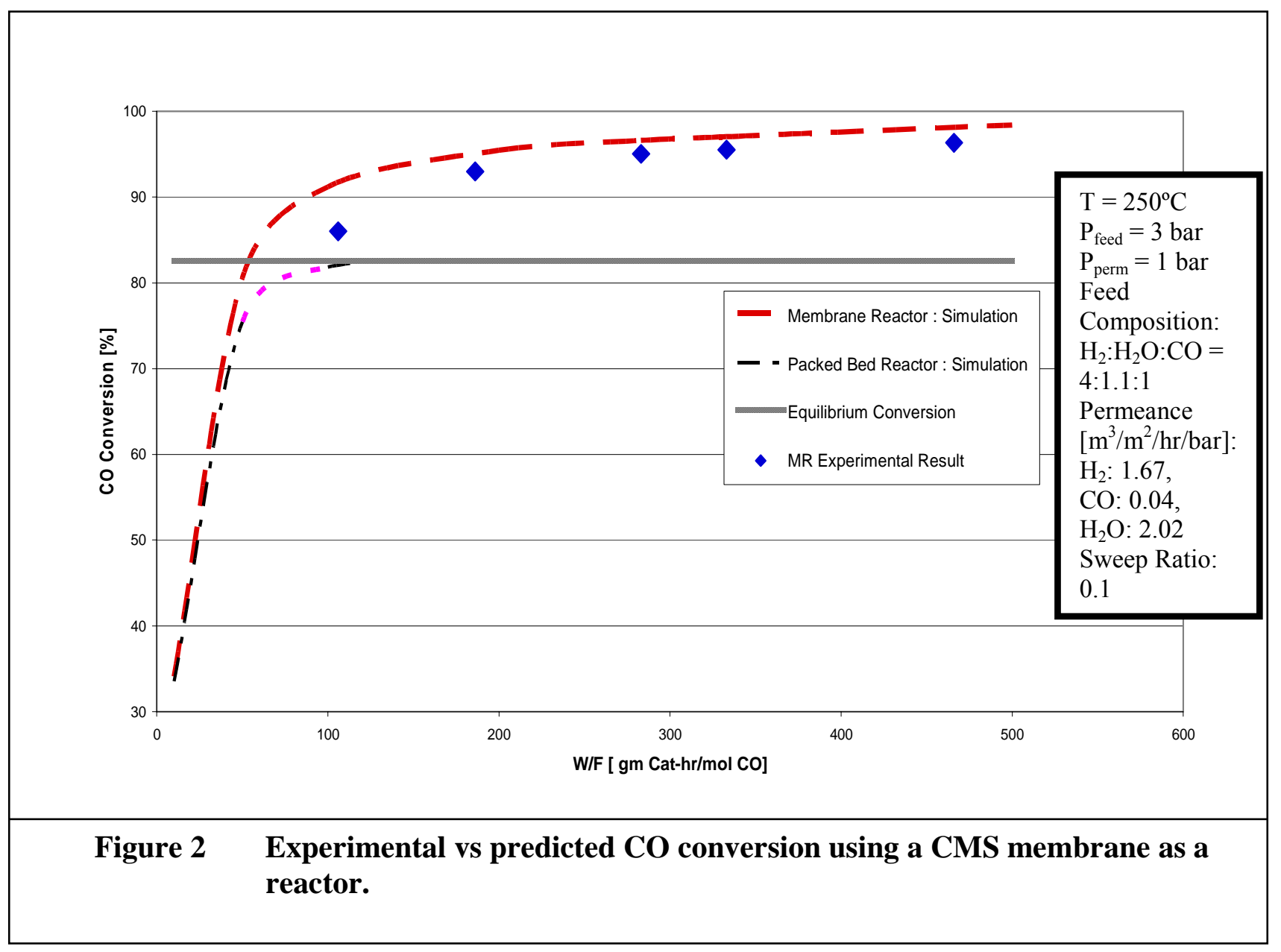




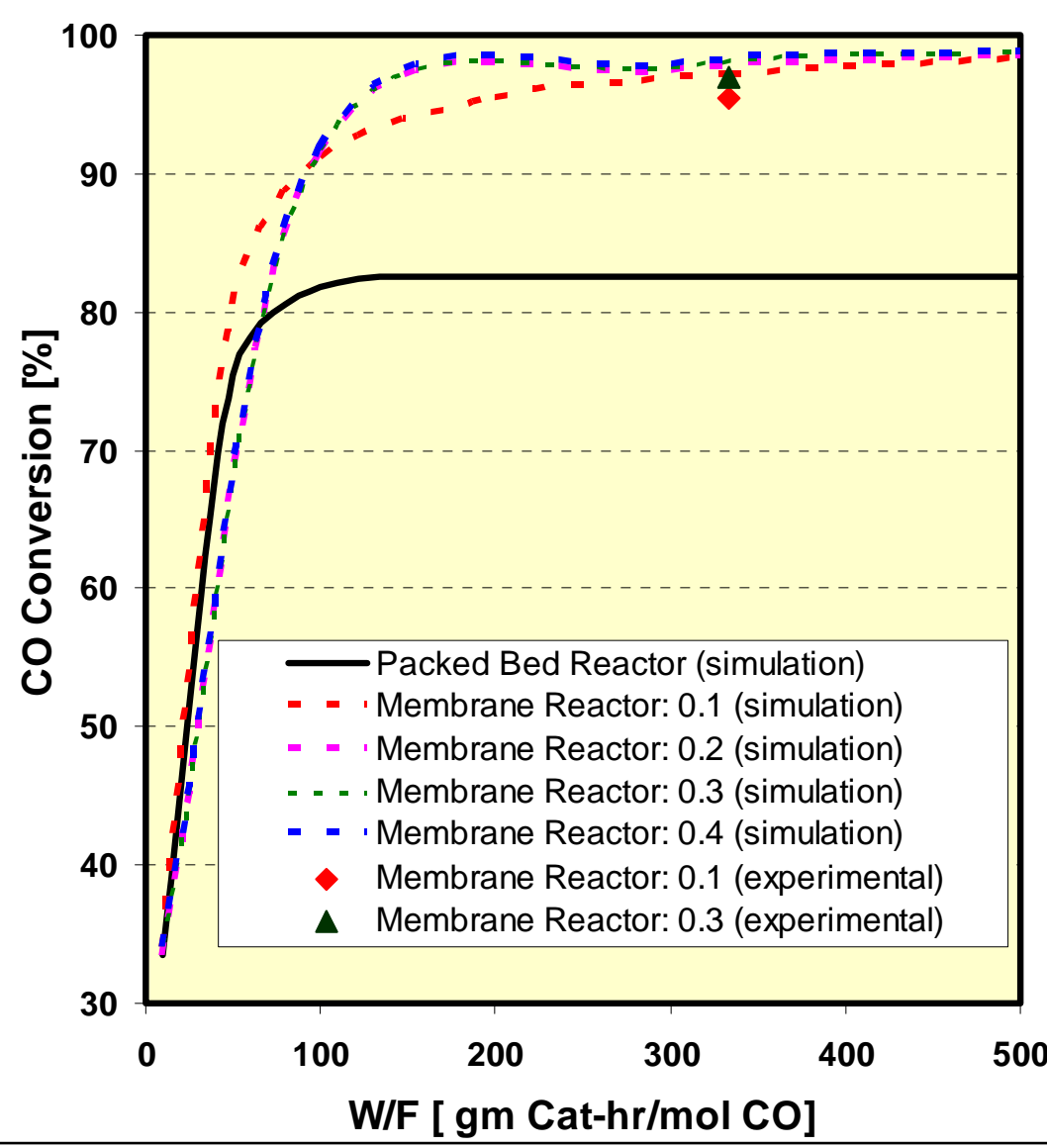

Figure 3

Effect of sweep ratio (as a fraction of the feed flow rate) on the CO conversion: experimental vs predicted. The feed condition used is the same as the one used for Figure 2

- Membrane Reactor: 0.4 (simulation)

- Membrane Reactor: 0.1 (experimental)

$\Delta$ Membrane Reactor: 0.3 (experimental)

W/F [ gm Cat-hr/mol CO] 


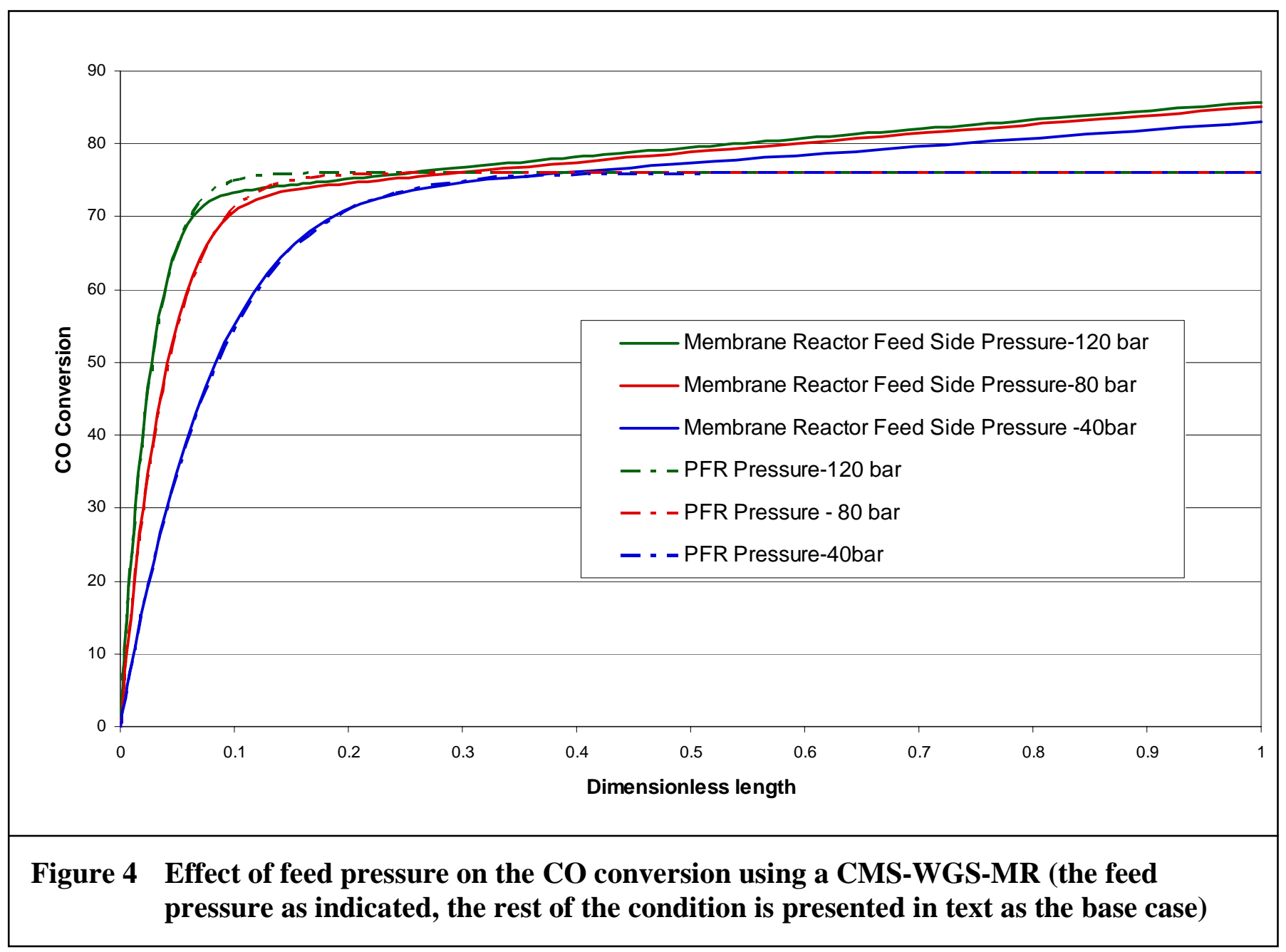




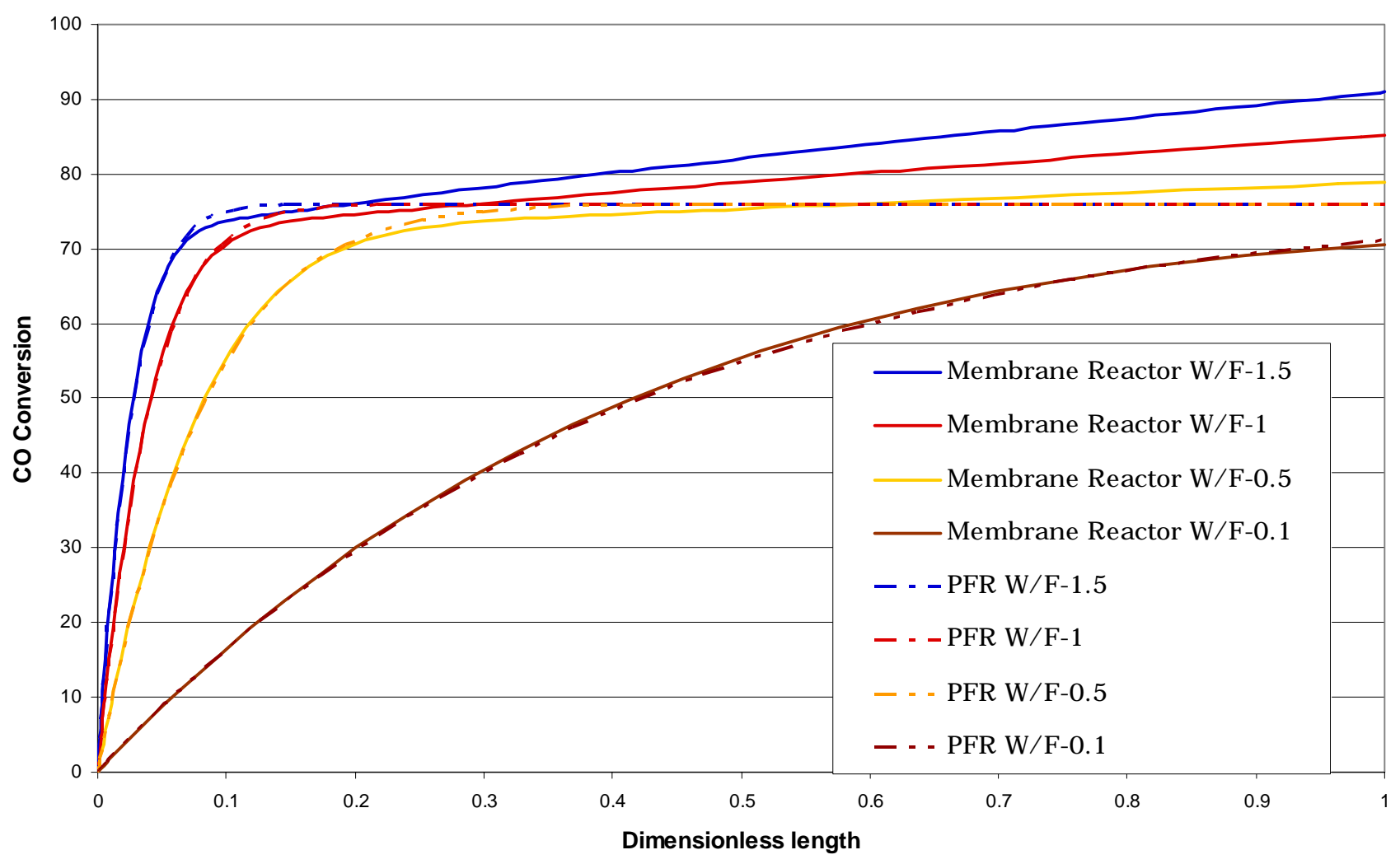

Figure 5 Effect of W/F on the CO conversion (the W/F used as noted, the rest of the operating condition is presented in the text as the base case) 


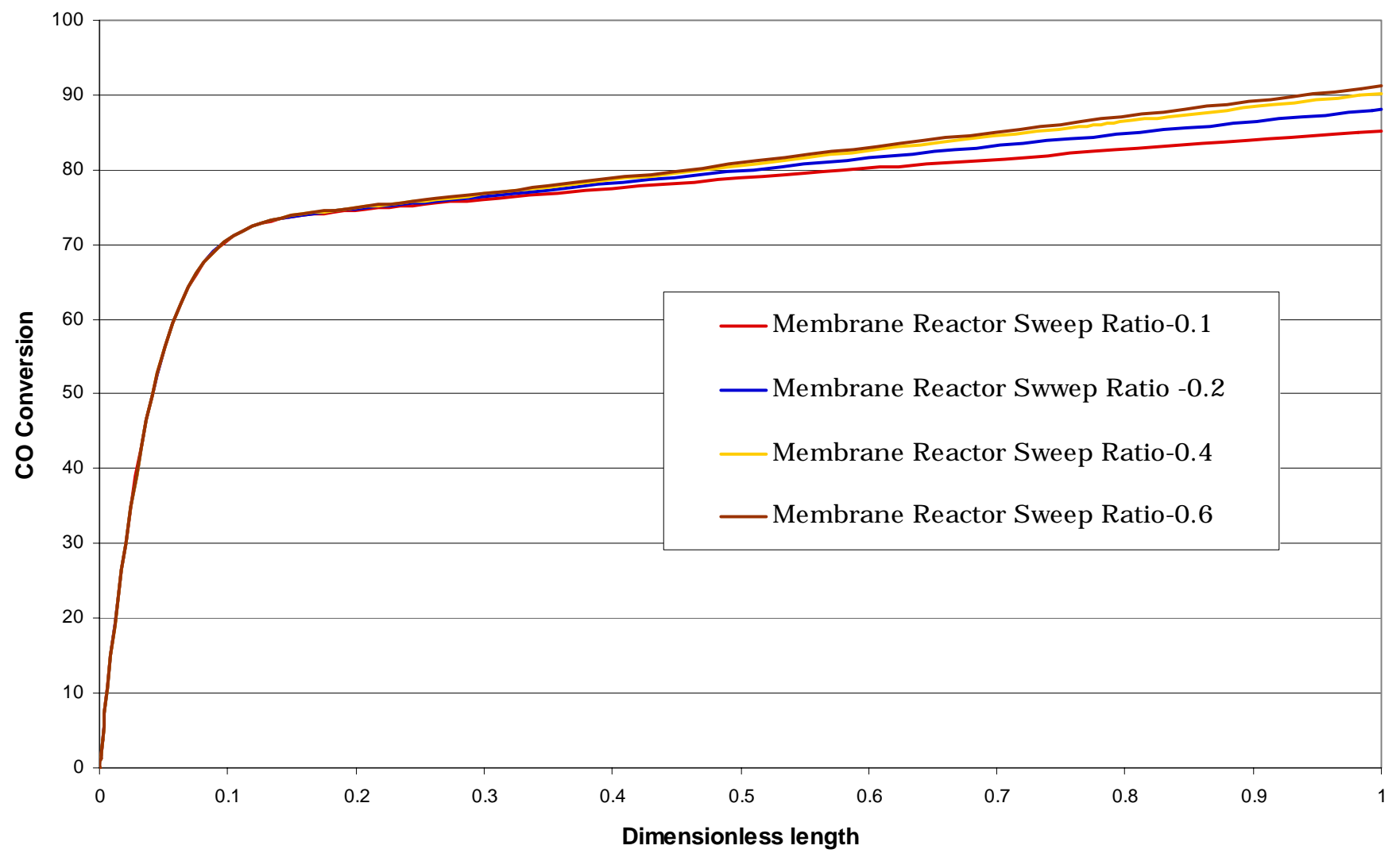

Figure 6 Effect of sweep ratio on the CO conversion (sweep ratio as a fraction of the feed stream as noted, the rest of the condition is presented in the text as the base case) 


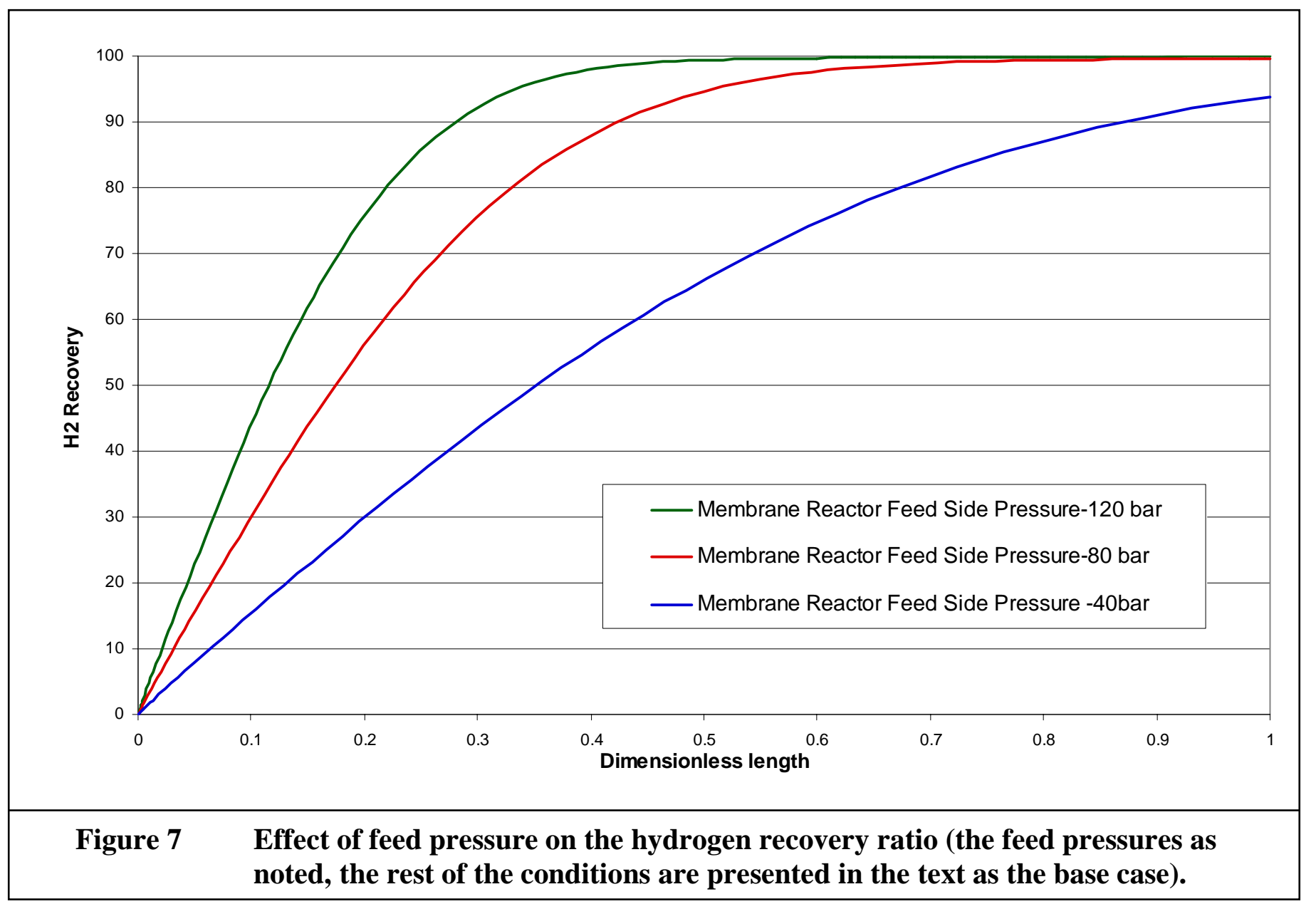




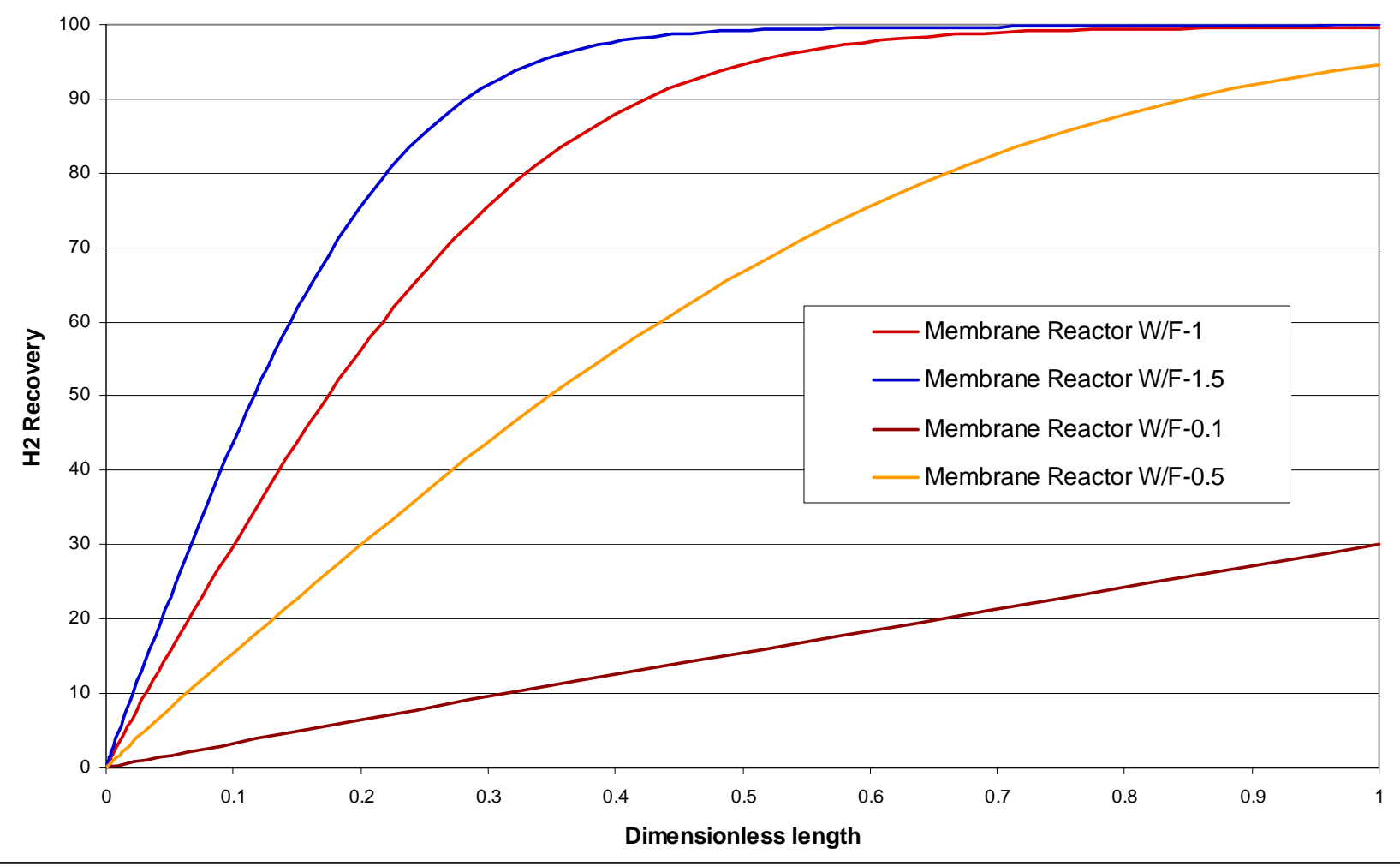

Figure 8 Effect of W/F on hydrogen recovery ratio (the W/F used as noted, the rest of the conditions are presented in the text as the base case) 


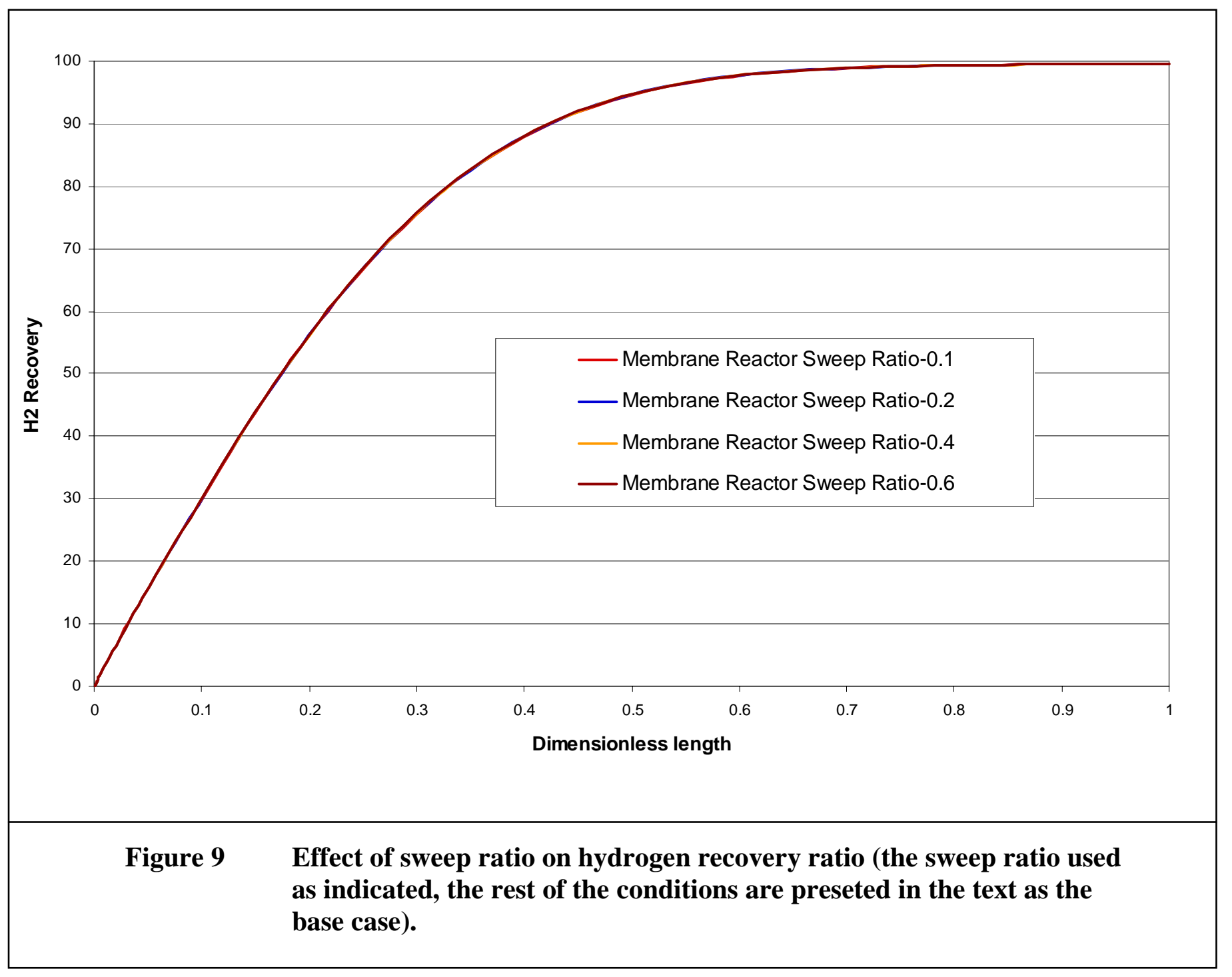




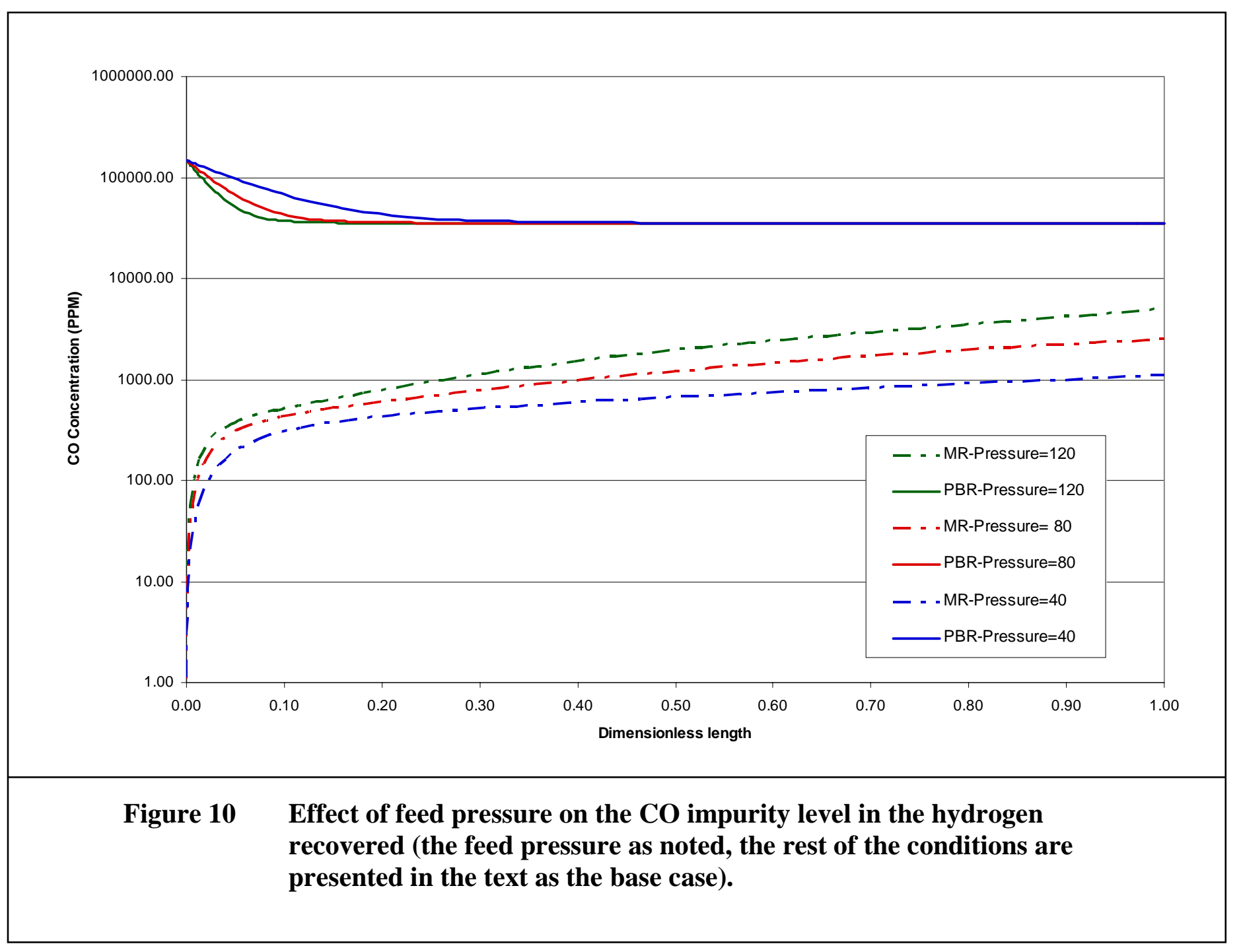



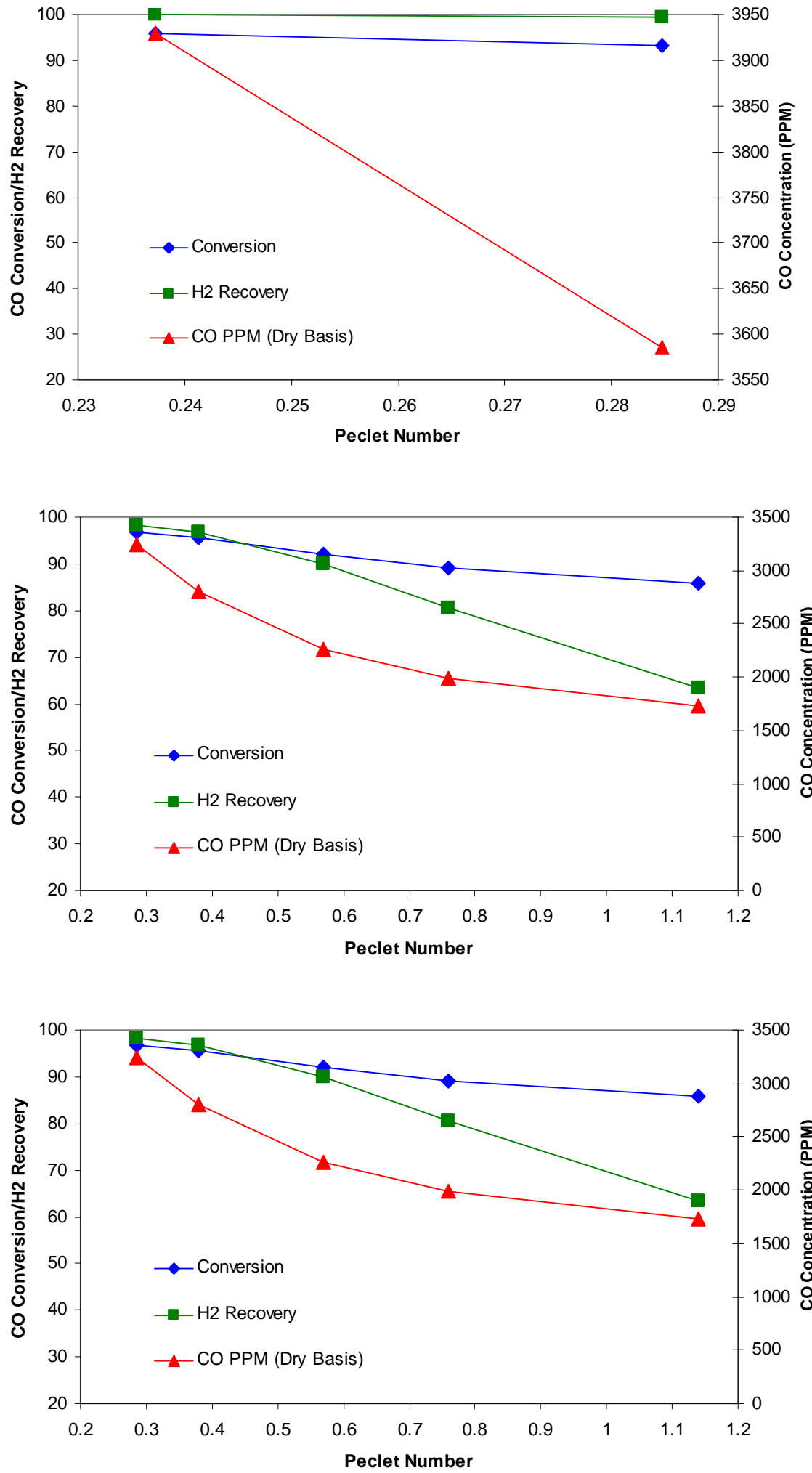

\section{Figure 11}

Preliminary optimization study on the proposed WGS-MR at 4 (top), 10 (middle) and 40 (bottom) bar feed pressure. The kinetics of the catalyst used here has not been verified at this high pressure range. Thus the optimization study here should be treated as preliminary. The Peclet number here represents the reactor length. The performance of $\mathrm{CO}$ conversion, hydrogen recovery and $\mathrm{CO}$ impurity are simulated against the membrane surface area for a given $\mathrm{W} / \mathrm{F}$ determined from the packed bed. 


\section{Conclusions}

Based upon the results obtained in this period, several conclusions can be drawn as follows:

- $\quad$ A prototype ceramic membrane bundle/element has been fabricated for full-scale applications. With the replacement of the existing epoxy potting with the high temperature ceramic potting, the element can now be used at temperature $>500-600^{\circ} \mathrm{C}$. Two bundle designs have been under preparation: heat exchanger-like and the candle filter-like. For the proposed applications at $200-300^{\circ} \mathrm{C}$, both designs are considered suitable.

- The burst pressure has been performed for the single element and bundle. The single element can take the pressure $>1500$ psi without burst. The bundle prepared during this period has the burst pressure at 500-750 psi. Although this pressure drop may be adequate for our proposed application, the bundle is under re-design with the objective of reaching the burst pressure of $>1000$ psi.

- A series of experimental study has been performed to verify the mathematical model prediction for the feed simulating the coal gasifier off-gas after bulk WGS conversion of $\mathrm{CO}$. The experimental results at various W/F's agree well with those obtained from the mathematical prediction. In addition the effect of sweep ratio on the $\mathrm{CO}$ conversion were experimentally performed; the results are consistent with the predicted conversion. Thus, we believe that the mathematical model we have developed is adequate for the simulation required by this project.

- Effect of several operating parameters, including feed pressure, W/F and the sweep ratio, on $\mathrm{CO}$ conversion, hydrogen recovery and $\mathrm{CO}$ impurity level have been studied comprehensively using the mathematical model. The W/F shows the most profound effect on the $\mathrm{CO}$ conversion and the $\mathrm{CO}$ impurity level. Further study indicates that the membrane surface area instead of the $\mathrm{W} / \mathrm{F}$ is in effect the key parameter which impact the $\mathrm{CO}$ conversion and $\mathrm{CO}$ impurity level.

- A preliminary optimization study has been performed in this period based upon the key operating parameters determined above. Our result shows that at 40 bar feed pressure a nearly complete $\mathrm{CO}$ conversion and $>95 \%$ hydrogen recovery can be achieved with the $\mathrm{CO}$ impurity level at $\sim 3500 \mathrm{ppm}$. If the hydrogen recovery ratio can be lowered, the $\mathrm{CO}$ impurity level can be reduced further. A comprehensive optimization study will be performed in the next reporting period. 
References:

None 


\section{List of Acronyms:}

WGS: water gas shift reaction

MR: membrane reactor

PFR: packed fixed-bed reactor

Ea: activation energy

HGCU: hot gas clean up

CMS: carbon molecular sieve

SGS: $\quad$ sour gas shift 